\title{
Tumor de células escamosas del pulmón
}

\section{Squamous cell tumor of the lung}

LILIANA FERNÁNDEZ T., MD.(1)

${ }^{(1)}$ Medicina Interna, Neumología, Neumología Intervencionista, Línea del Investigación Biomédica en Tórax, Fundación Valle del Lili. Profesora Clínica Asociada, Facultad de Ciencias de la Salud, Universidad Icesi. Cali-Colombia.

Correspondencia: Liliana Fernández T., correos electrónicos: 1fernandez@fcvl.org, lilianafernandeztrujillo@gmail.com Recibido: 20/10/16. Aceptado: 15/11/16.
Paciente de 84 años con antecedente de tabaquismo activo de una cajetilla diaria de cigarrillos, quien consultó con historia de pérdida de peso, tos con expectoración hemoptoica y dolor incapacitante en la escápula derecha y el área costal izquierda, de dos meses de evolución. Se le halló adelgazado con disminución generalizada de los ruidos respiratorios y con dolor en las áreas comprometidas de la pared del tórax y la escápula.
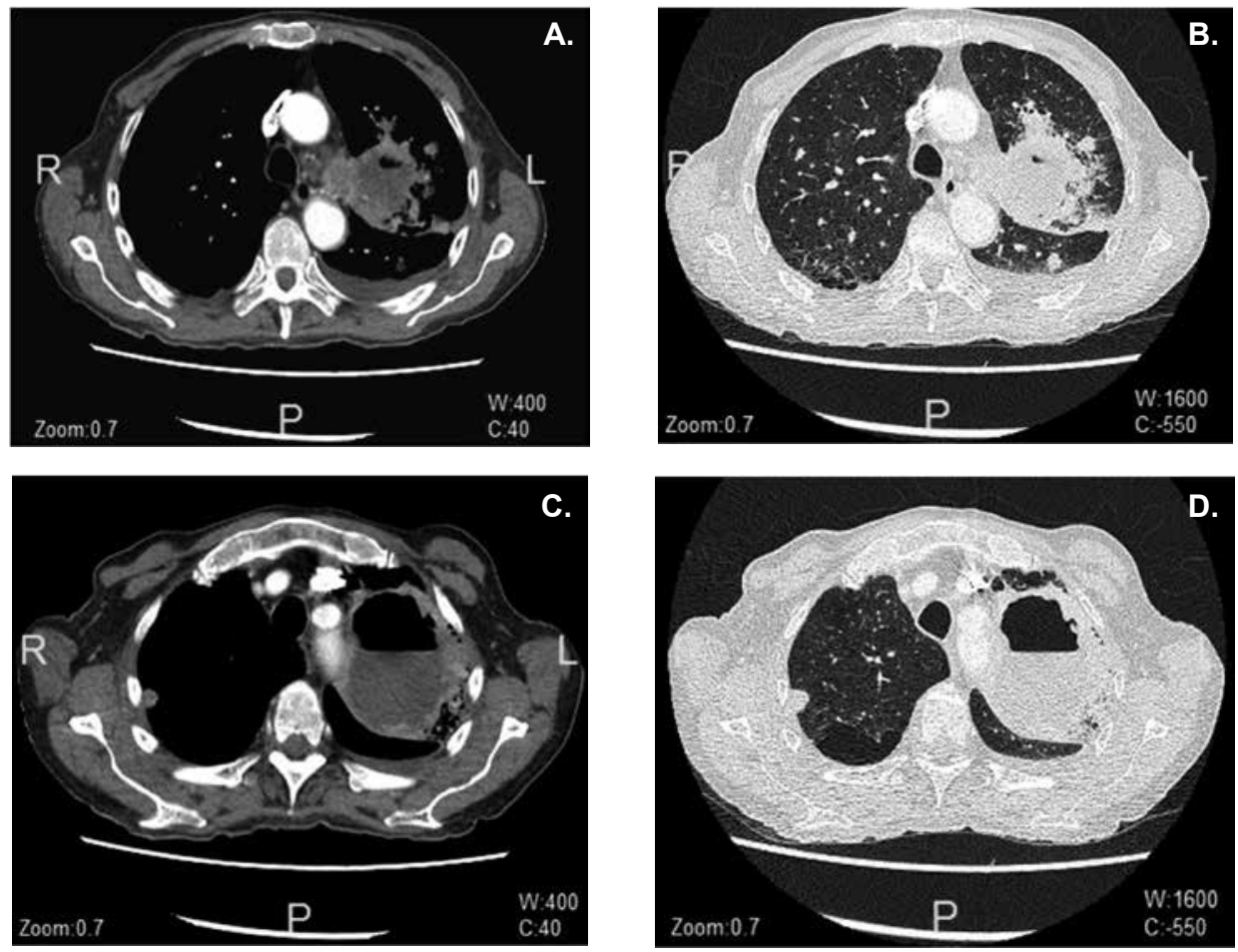

Figura $1 \mathrm{~A}, \mathrm{~B}, \mathrm{C}, \mathrm{D}$. TAC de tórax en ventana para mediastino y parapulmón donde se aprecia la lesión de aspecto tumoral cavitada en el lóbulo superior izquierdo, con compromiso del hilio y la cisura, nódulos pulmonares múltiples y compromiso óseo metastásico. 
Se realizó fibrobroncoscopia en la que encontró carina principal de aspecto normal y masa de aspecto tumoral que ocluía el bronquio del lóbulo superior izquierdo, la cual se resecó con criosonda. Al interior de la lesión cavitada se observó material purulento y se dejó permeable el bronquio (figura 2).
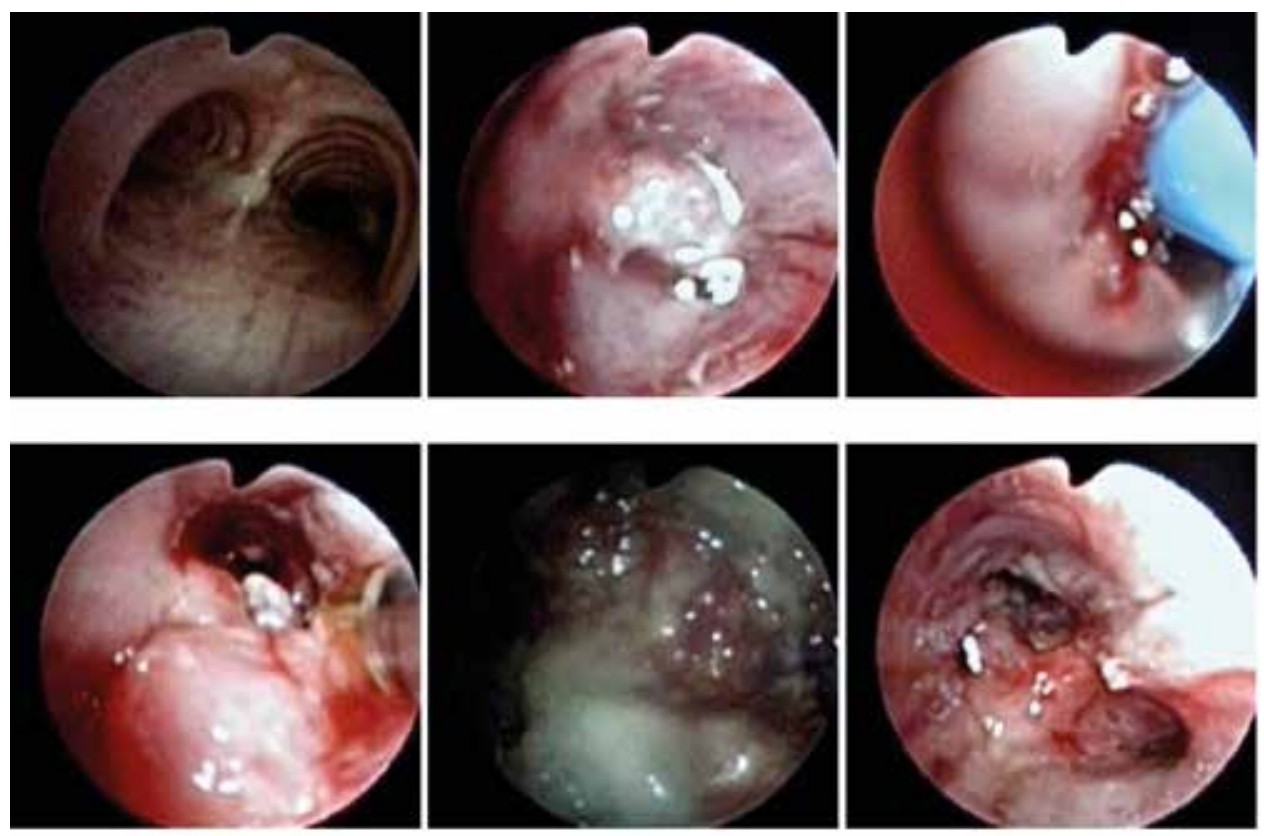

Figura 2. Aspecto endoscópico donde se encuentra masa en LSI, que se reseca con criosonda, quedando permeable. Se aprecia el interior de la masa con material purulento.

El diagnóstico histológico por H\&E e inmunohistoquímica fue tumor escamocelular moderadamente diferenciado con necrosis celular extensa. Posteriormente presentó deterioro y hemoptisis, por lo cual se le realizó una nueva broncoscopia donde se apreció el interior de la gran masa tumoral después de aspirar abundante cantidad de coágulos (figuras $3 \mathrm{~A}, \mathrm{~B}$ ).
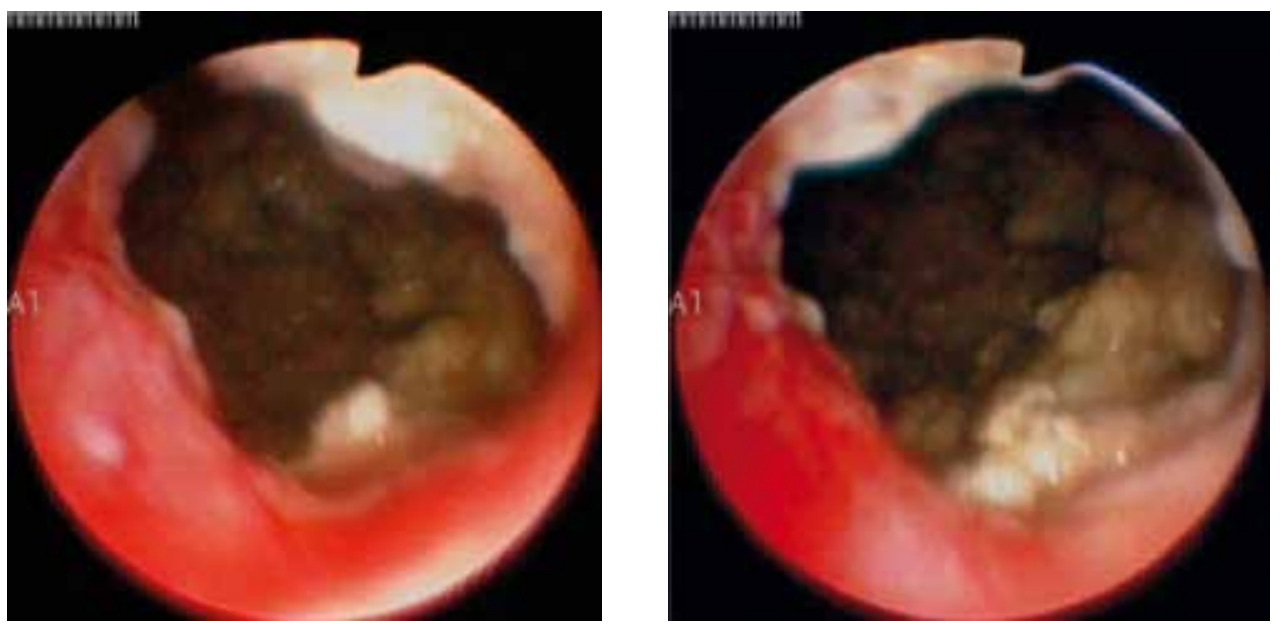

Figura 3 A, B. Aspecto endoscópico del interior de la cavidad del carcinoma escamocelular moderadamente diferenciado. 